\title{
Complement and contact activation in term neonates after fetal acidosis
}

\author{
Josef Sonntag, Mathias H Wagner, Evelyn Strauss, Michael Obladen
}

\begin{abstract}
Aims-To evaluate complement and contact activation after fetal acidosis. Methods-Fifteen term neonates with hypoxic-ischaemic encephalopathy after umbilical arterial $\mathrm{pH}<7.10$ were compared with 15 healthy neonates with umbilical arterial pH $>$ 7.20. Determinations of the complement function and C1-inhibitor activity were performed as kinetic tests 22-28 hours after birth. C1q, C1-inhibitor, and factor $B$ concentrations were determined by radial immunodiffusion and those of C3a, C5a, and factor XIIa by enzyme immunoabsorbent assay.

Results-Median complement function (46 vs $73 \%$ ), C1q (4.3 vs $9.1 \mathrm{mg} / \mathrm{dl})$, and factor B (5.2 vs $7.7 \mathrm{mg} / \mathrm{dl})$ decreased after fetal acidosis. The activated split products C3a (260 vs $185 \mu \mathrm{g} / 1)$, C5a (5.0 vs $0.6 \mu \mathrm{g} / 1)$, and factor XIIa (3.2 vs $1.3 \mu \mathrm{g} / \mathrm{l})$ increased in the neonates after fetal acidosis. No differences were found in the concentration and activity of C1-inhibitor.

Conclusions-Complement and contact activation occurred in the newborns with hypoxic-ischaemic encephalopathy. Activation of these systems generates mediators which can trigger inflammation and tissue injury.

(Arch Dis Child Fetal Neonatal Ed 1998;78:F125-F128)
\end{abstract}

Keywords: birth asphyxia; complement activation; contact activation; fetal acidosis

The complement and contact systems are activated after ischaemia and reperfusion injury, for example, myocardial infarction, ${ }^{12}$ cardiac surgery with cardiopulmonary bypass, ${ }^{34}$ or liver transplantation. ${ }^{56}$ Fetal acidosis, as a marker for uteroplacental insufficiency, is associated with hypoxia and reperfusion injury in neonates. ${ }^{7}$ Complement and contact components in these babies have not been systematically investigated.

This study aimed to assess complement and contact system activation in term neonates with hypoxic-ischaemic encephalopathy after fetal acidosis by examining several complement components and factor XIIa (Hageman factor) (figs 1 and 2).

\section{Methods}

The study was approved by the local ethics committee and written parental consent obtained. Inclusion criteria for the study group were: an umbilical arterial $\mathrm{pH}<7.10$ and hypoxic-ischaemic encephalopathy 20 hours after birth. ${ }^{8}$ Grade of hypoxic-ischaemic en- cephalopathy, renal function (diuresis by weighing the nappies and serum creatinine 24 hours after birth), coagulation disorders (prolonged clinical bleeding time, decrease in platelets, evidence of fibrin split products) and duration of mechanical ventilation were recorded. Seventeen neonates, admitted to our neonatal intensive care unit between July 1995 and March 1996, fulfilled the inclusion criteria. Because two sets of parents did not give their consent, the study involved 15 infants with a median gestational age of 39 weeks (range 37-41). None of patients had evidence of infection (C-reactive protein $>0.5 \mathrm{mg} / \mathrm{dl} 24$ hours after birth or positive blood culture). Fifteen healthy term neonates without perinatal complications, with the same gestational age, and an umbilical arterial $\mathrm{pH}>7.20$ were enrolled in the control group at the same time.

The study group were monitored to maintain mean arterial blood pressure, body temperature, normoglycaemia, normocalcaemia, normoxaemia, and normocapnia. Therapeutic interventions included infusion of fluids, mechanical ventilation, and administration of glucose and calcium. Five infants with convulsions were treated with phenobarbital, three received erythrocyte transfusion because of anaemia within the first 24 hours. Eleven infants were given pasteurised plasma solutions (Biseko, Biotest, Dreieich, Germany) for volume expansion. None of the patients received dexamethasone.

Blood samples were taken 22-28 hours after birth. Samples of blood $(0.4 \mathrm{ml})$ were collected in two tubes containing either disodiumethylene diamine tetra acetic acid (EDTA; Kabi-Labortechnik, Germany) or $0.07 \mathrm{ml}$ sodium citrate (Fa; Saarstedt, Germany) and within 20 minutes centrifuged for 5 minutes at $3000 \mathrm{rpm}$. The plasma was immediately

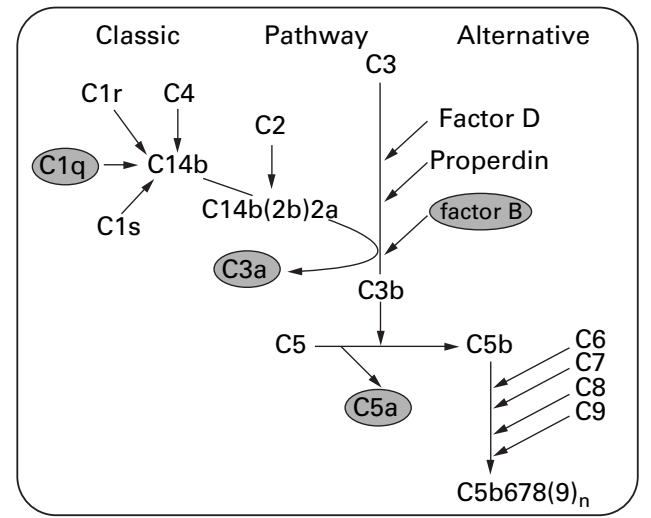

Figure 1 Complement system activation. 


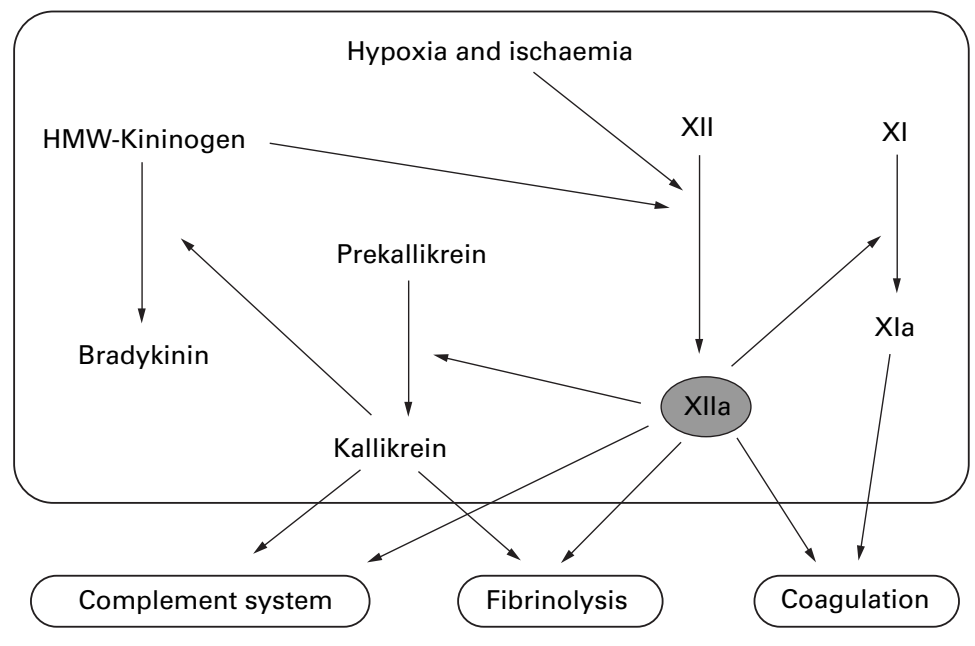

Figure 2 Contact system activation and its influence on complement system.

separated and stored at $-80^{\circ} \mathrm{C}$ for not longer than one month.

The reliability of the test results was routinely monitored using controls with known concentrations or activities. The bioassays were tested without prior knowledge of group assignment or clinical data.

Kinetic determination of the functional whole complement activity is based on the lysis of sensitised sheep erythrocytes (Behring Diagnostica AG, Marburg, Germany) by the activated complement factors in the plasma sample. The test measures the time needed for a total lysis of a fixed number of erythrocytes, which is indicated photometrically at $578 \mathrm{~nm} .{ }^{9}$ An intra-assay precision study $(n=20)$ showed a coefficient of variation of $5 \%$ using a standard plasma with $50 \%$ complement function.

Concentrations of C1-inhibitor, C1 q, and factor $\mathrm{B}$ were determined with single radial immunodiffusion using the Nor-Partigen kit (Behring Diagnostica AG, Marburg, Germany). ${ }^{10}$ The immunodiffusion diameter was corrected using a standard curve in a semilogarithmic plot. In intra-assay precision studies coefficients of variation $(n=20)$ were: $4 \%$ for a concentration of $5 \mathrm{mg} / \mathrm{dl}$ for $\mathrm{C} 1 \mathrm{q} ; 3 \%$ for $8.0 \mathrm{mg} / \mathrm{dl}$ for factor $\mathrm{B}$; and $6 \%$ for $0.10 \mathrm{~g} / 1$ for C1-inhibitor. The concentrations used to

Table 1 Clinical data of acidosis and control group (median with quartiles)

\begin{tabular}{lccl}
\hline & Acidosios group $(n=15)$ & Control group $(n=15)$ & $p$ Value \\
\hline Gestational age (weeks) & $39(38 / 40)$ & $39(38 / 40)$ & NS \\
Birthweight (g) & $3470(3180 / 3655)$ & $3560(2850 / 3820)$ & NS \\
Umbilical arterial pH & $6.96(6.90 / 7.05)$ & $7.32(7.29 / 7.36)$ & $<0.0001$ \\
Apgar 1 minute & $2(1 / 3)$ & $9(9 / 9)$ & $<0.0001$ \\
Apgar 5 minutes & $5(2 / 7)$ & $10(10 / 10)$ & $<0.0001$ \\
Apgar 10 minutes & $7(4 / 8)$ & $10(10 / 10)$ & $<0.0001$ \\
\hline
\end{tabular}

Table 2 Comparison of concentration and activities of complement factors and Hageman factor between acidosis and control groups (median with quartiles)

\begin{tabular}{lccl}
\hline & Acidosios group $(n=15)$ & Control group $(n=15)$ & $p$ Value \\
\hline Complement function test $(\%)$ & $46(24 / 52)$ & $73(60 / 90)$ & 0.001 \\
C1q concentration $(\mathrm{mg} / \mathrm{dl})$ & $4.3(3.5 / 5.7)$ & $9.1(8.2 / 9.7)$ & $<0.0001$ \\
Factor B $(\mathrm{mg} / \mathrm{dl})$ & $5.2(4.3 / 7.9)$ & $7.7(6.9 / 9.3)$ & 0.02 \\
C3a $(\mu \mathrm{g} / \mathrm{l})$ & $260(180 / 705)$ & $185(100 / 260)$ & 0.04 \\
C5a $(\mu \mathrm{g} / \mathrm{l})$ & $5.0(0.6 / 10.5)$ & $0.6(0.55 / 1.2)$ & 0.005 \\
Factor XIIa $(\mu \mathrm{g} / \mathrm{l})$ & $3.2(1.3 / 6.4)$ & $1.3(0.8 / 1.9)$ & 0.02 \\
C1 inhibitor concentration $(\mathrm{g} / \mathrm{l})$ & $0.12(0.08 / 0.15)$ & $0.12(0.10 / 0.16)$ & $\mathrm{NS}$ \\
C1 inhibitor activity $(\%)$ & $65(55 / 103)$ & $75(55 / 110)$ & $\mathrm{NS}$ \\
\hline
\end{tabular}

determine the coefficients of variation were within the normal range for neonatal plasma.

C3a enzyme immunoassay (EIA, Fa. Progen Biotechnik $\mathrm{GmbH}$, Heidelberg, Germany) selectively detects C3a-desArg using monoclonal antibodies. ${ }^{11}$ The variation coefficient (n $=20$ ) for a concentration of $550 \mu \mathrm{g} / 1$ was $8 \%$ for this method. C5a was determined using a specific sandwich EIA (Fa. Behring, Marburg, Germany) and showed a variation coefficient $(\mathrm{n}=20)$ of $8 \%$ for a concentration of $5 \mu \mathrm{g} / \mathrm{l}^{12}$

The concentration of activated factor XIIa was measured using a semiquantitative direct immunoassay with specific sheep monoclonal antibodies (WAK-Chemie Medical $\mathrm{GmbH}$, Bad Homburg, Germany). ${ }^{13}$ The intra-assay coefficient of variation $(\mathrm{n}=20)$ for $\mathrm{a}$ concentration of $10 \mu \mathrm{g} / 1$ was $6 \%$.

The functional activity of the C1-inhibitor was determined in citrated plasma by using the chromogenic substrate technique described by Heber et al (Behring Diagnostica AG, Marburg, Germany). ${ }^{14}$ The coefficient of variation in an intra-assay precision study for a standard plasma with an activity of $95 \%$ was $5 \%$.

As most of the data were not distributed normally, results were expressed as medians with quartiles. Differences between the two groups were assessed using the Mann-Whitney U test. Significance was assumed at $\mathrm{p}<0.05$. All calculations and tests were carried out using the software package SPSS-PC (Chicago, Illinois USA).

\section{Results}

Clinical data from the study and control group are shown in table 1 . Ten neonates from the study group developed grade I hypoxicischaemic encephalopathy, three grade II, and two grade III. Five neonates from the study group had renal failure in the first 48 hours, characterised by diuresis $<1.0 \mathrm{ml} / \mathrm{kg} /$ hour and serum creatinine $>120 \mu \mathrm{mol} / \mathrm{l}$. Four developed a coagulation disorder in the first three days of life. Nine neonates were intubated at birth and artificially ventilated for 0.5 to 168 hours, two of them developed clinical and radiological signs of surfactant deficiency. None of the infants died before being discharged from hospital. None of the infants from the control group had clinical symptoms of hypoxicischaemic encephalopathy, respiratory distress, coagulation disorders, or renal failure.

The study group showed decreased functional activity of the whole complement system as well as decreased plasma concentrations of $\mathrm{C} 1 \mathrm{q}$ and factor B. Higher amounts of activated split products $\mathrm{C} 3 \mathrm{a}, \mathrm{C} 5 \mathrm{a}$ and factor XIIa were found in this group than in the control group. No difference in concentration or functional activity of C1-inhibitor was found between the study and control groups (table 2).

\section{Discussion}

Brain damage after severe fetal acidosis may affect the entire life of the child. Many studies have investigated the pathophysiology of the developing tissue injury based on hypoxia and ischaemia and its therapeutical prevention in affected neonates. Aprimary problem is to 
detect those babies likely to be at risk. Low umbilical arterial $\mathrm{pH}$ and Apgar score are the traditionally used definitions of fetal acidosis, but they are poor predictors of latent disability in surviving infants. ${ }^{15} 16$ The best predictors of death or handicap are neurological symptoms in the early neonatal period referred to as hypoxic-ischaemic encephalopathy. ${ }^{17}{ }^{18}$ Therefore, in this study we investigated only those neonates with both fetal acidosis and development of hypoxic-ischaemic encephalopathy within 20 hours of birth.

In the study group concentrations of $\mathrm{C} 1 \mathrm{q}$ and factor B in plasma as well as haemolytic activity of the complement system were lower than in the control group. The reasons for the diminished values may be the consumption of the native complement proteins following complement activation, or reduced protein synthesis due to transient liver failure or a combination of both. To verify the complement activation we determined the activated split products acting as anaphylatoxins. $\mathrm{C} 3 \mathrm{a}$ and $\mathrm{C} 5 \mathrm{a}$ both increased after fetal acidosis. Schrod et $a l^{19}$ reported increased $\mathrm{C} 3$ a concentrations in preterm neonates with adult respiratory distress syndrome due to the surfactant inactivation after shock. We found increased C3a concentrations in acidotic neonates with $(n=2)$ and without $(n=13)$ respiratory distress syndrome. The increased C5a after fetal acidosis indicates an enhanced production, because $\mathrm{C} 5 \mathrm{a}$ first binds to granulocyte receptors and only the free anaphylatoxin molecules were found in plasma. ${ }^{4}$ Considering the increased anaphylatoxin concentrations, as well as decreased function and concentration of native proteins, we assumed that the complement system is activated after birth acidosis. Because the complement activation was evident 22 to 28 hours after birth, the effect of therapeutic interventions on the complement system activation within this time frame cannot be excluded. However, we found no differences between the infants who were treated with phenobarbital, transfusion, or pasteurised plasma solutions and those who were not in the study group. None of the study infants received drugs or acute interventions that are reported to influence the immune system. Thus the main reason for the complement activation is probably cell disintegration. Ischaemia releases subcellular constituents-mostly mitochondrial proteins - which bind to $\mathrm{C} 1 \mathrm{q}$ and activate the complement cascade in vitro and in vivo. ${ }^{2021}$ Another reason for complement activation is the loss of protective membrane proteins on injured cells, which may be due to the activation of complement cascade in the ischaemic area. ${ }^{22} 23$

The complement system has a major role in initiating some of the inflammatory events occurring in ischaemia and reperfusion after myocardial infarction, cardiopulmonary bypass surgery, and liver transplantation..$^{2-4} 624$ Anaphylatoxins contribute to an increased permeability of small blood vessels, the contraction of smooth muscles, the release of histamine, the secretion of lysosomal enzymes and cytokines as well as granulocyte migration and adher- ence. Another aspect of the complement activation is the direct cytotoxic effect of the membrane attack complex on endothelial cells. $^{2}$ All these mechanisms may enhance tissue injury following ischaemia and reperfusion. ${ }^{22} 2526$

The increased concentrations of factor XIIa in the study group may be explained by contact activation after fetal acidosis. The reason for this activation likely is the contact of factor XII with negatively charged surfaces or cell constituents after cell destruction. Additionally, the contact system is activated by hypoxanthine, ${ }^{27}$ which increases after birth asphyxia. $^{28}$ The activated contact or kinin system is involved in inflammatory tissue injury through bradykinin and kallikrein release with increased vascular permeability, leucocyte accumulation, and arterial hypotension. The contact system is closely related to the complement system, and mutual activation is possible. ${ }^{27}$ Additionally, factor XIIa influences coagulation and fibrinolysis, ${ }^{27}$ which act simultaneously after birth asphyxia. ${ }^{29}$ Thus increased values of factor XIIa can contribute to the development of disseminated intravascular coagulation disorders in acidotic neonates.

Activation of the complement and contact system is controlled by rapid binding of $\mathrm{C} 1$-inhibitor to factor $\mathrm{C} 1$ and factor XIIa. ${ }^{30} \mathrm{We}$ therefore expected decreased concentration and activity in the study group after complement and contact activation. But the values were no different from those of the control group despite complement activation. This may be due to increased synthesis of this acute phase protein after asphyxia. ${ }^{30}$ However, the additional amount of C1-inhibitor produced could not prevent the activation of both systems.

Complement and contact activation occur in neonates with hypoxic-ischaemic encephalopathy after fetal acidosis. Whether such activation causes tissue damage is not proved by our data, but it generates mediators which can promote inflammation and may contribute to the pathogenesis of reperfusion injury.

This work was supported by the German Research Society (DFG-Ob 43/6-2)

1 Buerke M, Murohora T, Lefer AM. Cardioprotective effects of a $\mathrm{C} 1$ esterase inhibitor in myocardial ischemia and reperfusion. Circulation 1995;91:393-402.

2 Homeister JW, Lucchesi BR. Complement activation and inhibition in myocardial ischemia and reperfusion injury. Annu Rev Pharmacol Toxicol 1994;34:17-40.

3 Seghaye MC, Duchateau J, Grabitz RG, et al. Complement, leukocytes, and leukocyte elastase in full-term neonates undergoing cardiac operation. F Thorac Cardiovasc Surg 1994;108:29-36.

4 Chenoweth DE, Cooper SW, Hugli TER, Stewart RW, Blackstone EH, Kirklin JW. Complement activation during cardiopulmonary bypass. $N$ Engl $\mathscr{f}$ Med during cardiopulm

5 Goldstein IM Complement.: Biologically active products. In: Gallin JL, Goldstein IM, Snyderman R, eds. Inflammation: Basic principles and clinical correlates. New York: Raven Press, 1992:63-80.

6 Chavez-Cartaya RE, De Sola GP, Wright L, et al. Regulation of the complement cascade by soluble complement receptor type 1. Protective effect in experimental liver ischemia and reperfusion. Transplantation 1995;59:1047-52.

7 Kjellmer I. Mechanisms of perinatal brain damage. Ann Med 1991;23:675-9.

8 Sarnat HB, Sarnat MS. Neonatal encephalopathy following fetal distress. Arch Neurol 1976;33:696-705.

9 Kolde HJ, Deubel R. Development of a rapid kinetic assay for the function of the classical pathway of the complement 
system and for $\mathrm{C} 2$ and $\mathrm{C} 4.7$ Clin Lab Immunol 1986;21:201-7.

10 Mancini G, Carbonara AT, Heremans JF. Immunochemical quantitation of antigens by single radial immunodiffusion.

11 Burger R, Zilow G, Bader A, et al. The C terminus of the anaphylatoxin $\mathrm{C} 3$ a generated upon complement activation represents a neoantigenic determinant with diagnostic potential. F Immunol 1988;141:553-8.

12 Klos A, Ihrig V, Messmer M, Grabbe J, Bitter-Suermann D Detection of native human complement componenets $\mathrm{C} 3$ and $\mathrm{C} 5$ and their primary activation peptides $\mathrm{C} 3 \mathrm{a}$ and $\mathrm{C} 5 \mathrm{a}$ (anaphylatoxic peptides) by ELISAs with monoclonal antibodies. F Immunol Methods 1988;111:241-52.

13 Ford RP, Esnouf MP, Burgess AI, Sarphie AS. An enzymelinked immunsorbent assay (ELISA) for the measurement of activated factor XII (Hageman factor) in human plasma. F Immunoassay 1996;17:119-31.

14 Heber H, Kolde HJ, Heimburger N, Svendsen G. A chromogenic substrate assay for C1-inhibitor. Thromb Haemostas 1983;50:227-30.

15 Marrin M, Paes BA. Birth asphyxia: does the Apgar score have diagnostic value? Obstet Gynecol 1988;72:120-3.

16 Thornberg E, Thiringer K, Odeback A, Milsom I. Birth asphyxia: incidence, clinical course and outcome in a Swedish population. Acta Paediatr 1995;84:927-32

17 Finer NN, Robertson CM, Peters KL, Coward JH. Factors affecting outcome in hypoxic-ischemic encephalopathy in term infants. Am F Dis Child 1983;137:21-5.

18 Robertson CMT, Finer NN, Grace MGA. School performance of survivors of neonatal encephalopathy associated with birth asphyxia at term. $\mathcal{F}$ Pediatr 1989;144:753-60

19 Schrod L, Frauendienst-Egger G, von Stockhausen HB, Kirschfink M. Plasma C3a in asphyxiated neonates. Eur $\mathcal{F}$ Pediatr 1992;151:688-92.

20 Giclas PC, Pinckard RN, Olson MS. In vitro activation of complement by isolated human heart subcellular membranes. F Immunol 1979;122:146-51.

21 Rossen RD, Michael LH, Kagiyima A, et al. Mechanism of complement activation after coronary artery occlusion:
Evidence that myocardial ischemia in dogs causes release of constituents of myocardial subcellular origin that complex with human Clq in vivo. Circ Res 1988;62:572-84. Morgan BP. Physiology and pathophysiology of comple-
ment: progress and trends. Crit Rev Clin Lab Sci ment: progress

23 Vakeva A, Morgan BP, Tikkanen I, et al. Time course of complement activation and inhibitor expression after ischemic injury of rat myocardium. Am $\mathcal{7}$ Pathol 1994;144:1357-68.

24 Saatvedt K, Lindberg H, Geiran OR, et al. Complement activation and release of tumour necrosis factor alpha, interleukin-2, interleukin-6 and soluble tumour necrosis factor and interleukin-2 receptors during and after cardiopulmonary byp

25 Murdoch J, Hall R. Brain protection: physiological and pharmacological considerations. Part I: The physiology of brain injury. Can $\mathcal{F}$ Anaesth 1990;37:663-71

26 Lucchesi BR Complement, neutrophils and free radicals: mediators of reperfusion injury. Arzneimittelforschung 1994;44:420-32.

27 Kozin F, Cochrane CG. The contact activation system of plasma: biochemistry and pathophysiology. In: Gallin JL, Goldstein IM, Snyderman R, eds. Inflammation: Basic principles and clinical correlates. New York: Raven Press, principles and

28 Pietz J, Guttenberg N, Gluck L. Hypoxanthine: a marker for asphyxia. Obstet Gynecol 1988;2:762-6.

29 Suzuki S Blood coagulation and fibrinolysis of the newborn viewed as perinatal factors. I.Blood coagulation and fibrinolysis of the newborn viewed as obstetrical factors. F Perinat Med 1977;6:274-83.

30 Eisel B, Delvos U. From localized angioedema to generalized capillary leak syndrome: evidence for a pivotal role of Cl-inhibit $\mathrm{K}$, Sprung $\mathrm{C}$, eds Sepsis: Current Perspectives in Pathophysiology and Therapy. Heidelberg: Springer-Verlag, 1994:501-27. 